\title{
Effects of Emergence Depth on Eleocharis kuroguwai Ohwi Response to Pyrazosulfuron-ethyl
}

\author{
Masaru Ogasawara,* Shin-ichiro Ogawa,* Masami Washino,* \\ Yasutomo Takeuchi* and Makoto Konnai*
}

Key words : emergence depth, Eleocharis kuroguwai, tuber, pyrazosulfuron-ethyl キーワード: 出芽深, クログワイ, 塊茎, ピラゾス ルフロンエチル

\section{Introduction}

Recently, much attention has been focused on Eleocharis kuroguwai Ohwi., a hygrophyte perennial, because the weed has appeared to be highly tolerant to chemical weeding ${ }^{2,5}$. Its physiological and ecological characteristics are different from those of other perennial paddy weeds such as Cyperus serotinus ${ }^{4}$ and Sagittaria pygmaea $^{3)}$, i. e., Eleocharis kuroguwai emerges continuously during the period of puddling to later growth stages of rice plants and from deeper in soil than others do. The intraspecific variation of the weed $^{1)}$ may also contribute to its herbicide tolerance. Under these circumstances, potent rice herbicides with broad herbicidal spectra have been developed, and their herbicidal activities against Eleocharis kuroguwai require examination.

The objectives of this study were to determine the effects of pyrazosulfuron-ethyl, ethyl 5-[[3-(4, 6-dimethoxypyrimidin-2-yl) ureido] sulfonyl]-1H-1-methylpyrazole-4-carboxylate, on tuberization of Eleocharis kuroguwai

小笠原勝・尾川新一郎 - 鷲野方美 - 竹内安智 - 近内誠登 : クログワイのピラゾスルフロンエチル感受性に及ぼす出芽 深の影響

* Weed Science Center, Utsunomiya University, 350 Mine-machi, Utsunomiya 321, Japan.

(Received December 11, 1990) emerging from various depths in soil, and to identify the major factors affecting its herbicidal efficacy.

\section{Materials and Methods}

Eleocharis kuroguwai tubers used in these experiments were collected from the paddy rice field of Utsunomiya University in February 1989 and were stored in moist moss at $5^{\circ} \mathrm{C}$ in the dark for 3 months. Pyrazosulfuron-ethyl was formulated as a $10 \%(w / w)$ wettable powder.

The tubers, fresh weight : $1.5 \sim 1.8 \mathrm{~g}$, were germinated in an incubator at $30^{\circ} \mathrm{C}$ in the dark until the plumules grew to about $1 \mathrm{~cm}$ long. Utsunomiya paddy soil (clay loam) sieved through a $0.5 \mathrm{~cm}$ i.d. screen was placed in a Wagner pot, $25 \mathrm{~cm}$ i.d., $30 \mathrm{~cm}$ tall, to a depth of $20 \mathrm{~cm}$. Eight germinated tubers were transplanted to each pot at 7.5 or $15 \mathrm{~cm}$ deep, and the pots were excessively watered to provide a water level of $3 \mathrm{~cm}$. Pyrazosulfuron-ethyl $(0.21 \mathrm{~g} / \mathrm{a})$ treatment was made just after the transplanting (pre-emergence treatment) or when the weeds emerged (post-emergence treatment). The number and fresh weight of the newly formed tubers were measured 6 months after treatment. In the pre-emergence treatment plots, the stem number was recorded at 5-day intervals during the 55 days following treatment. A compound fertilizer $(\mathrm{N}: \mathrm{P}: \mathrm{K}=8: 8: 8,3 \mathrm{~g} / \mathrm{pot})$ was added to the pots at the time soil was put in and again 3 months after treatment.

Throughout the experiments, the pots were 


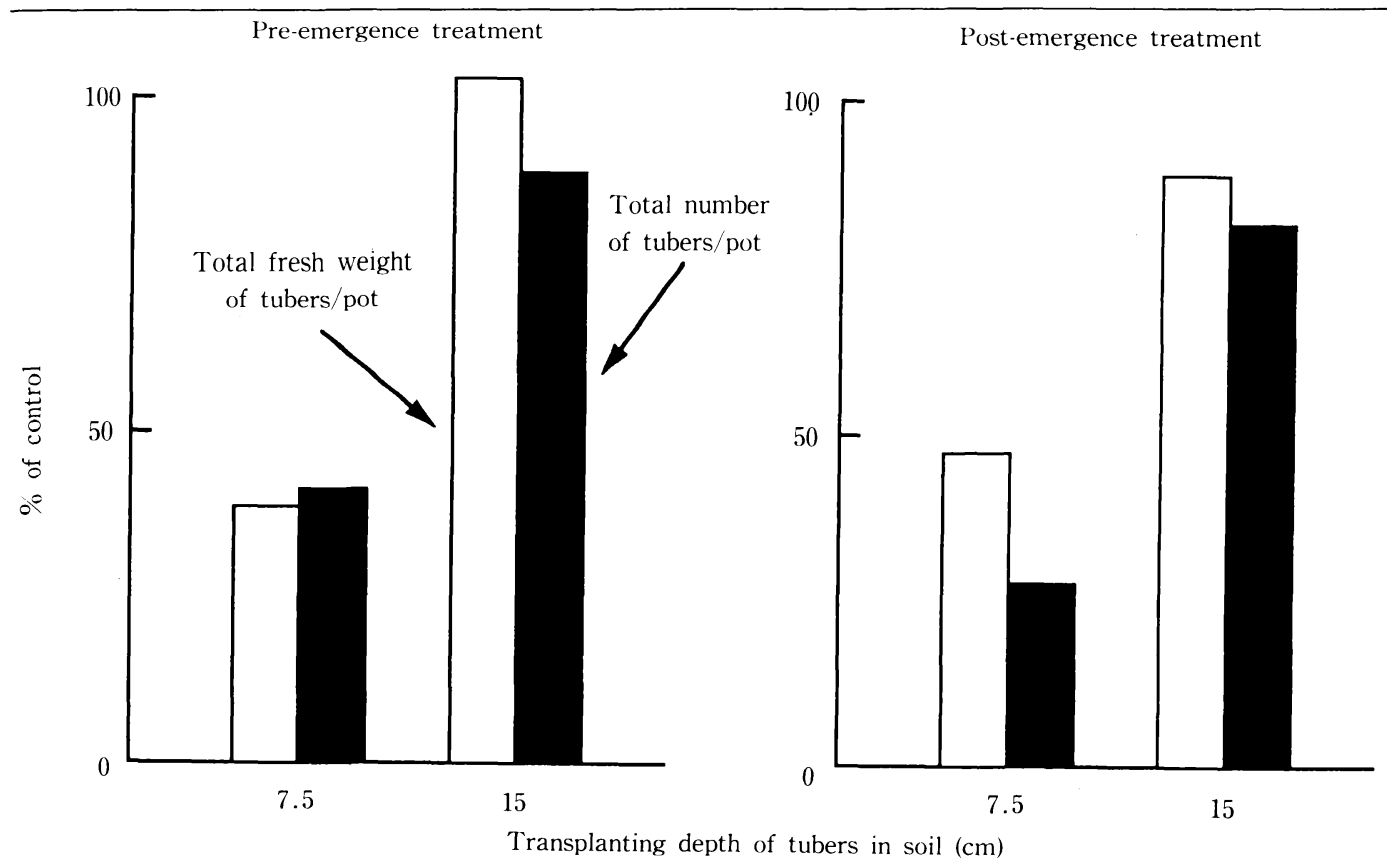

Fig. 1. Effect of pyrazosulfuron-ethyl $(0.21 \mathrm{~g} / \mathrm{a})$ on the tuber formation of Eleocharis kuroguwai by pre-emergence and post-emergence treatments.

The number and the fresh weight of tubers was measured 6 months after treatments.
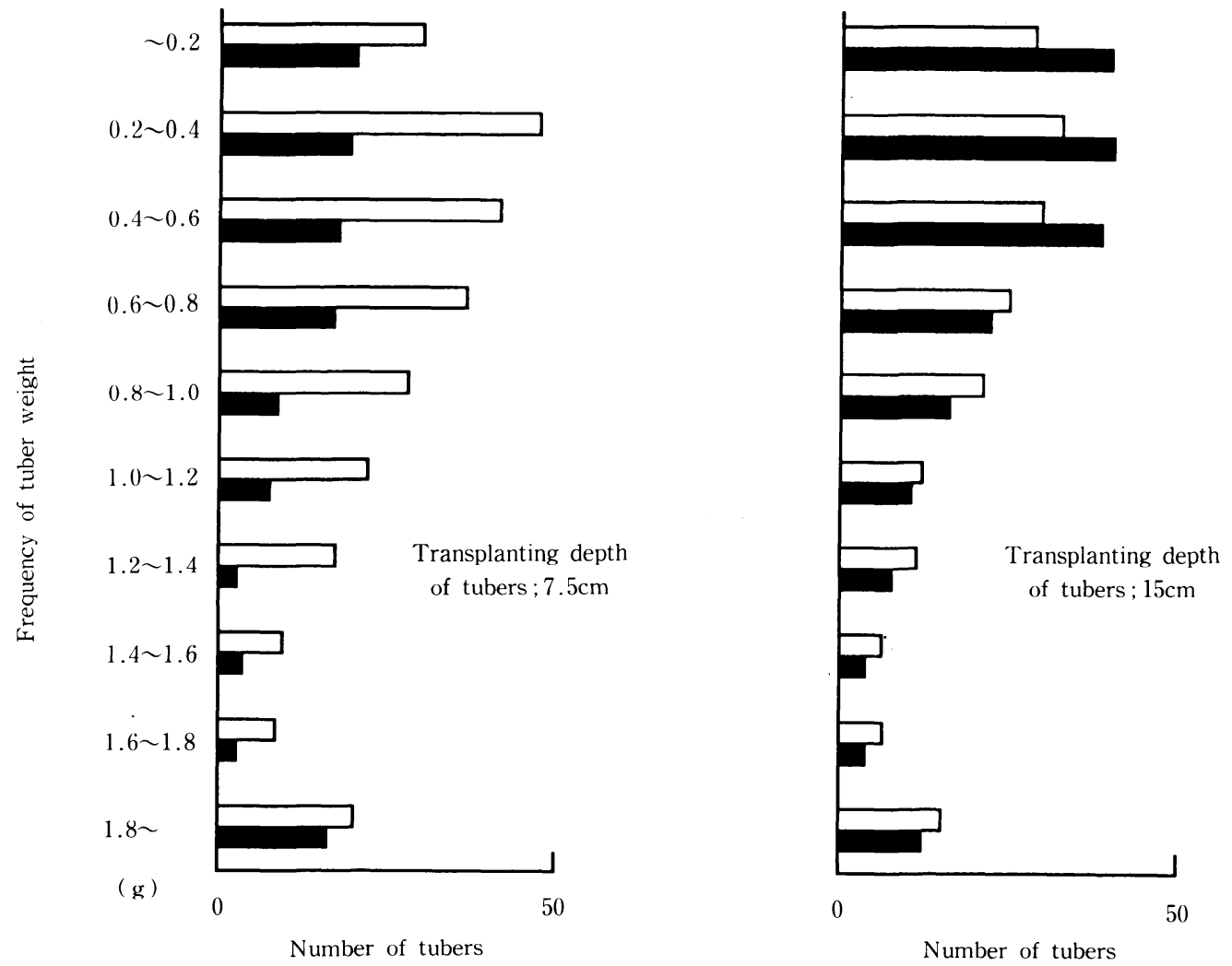

Fig. 2. Frequency distribution of tuber weight of Eleocharis kuroguwai after pre-emergence treatment with $0.21 \mathrm{~g} / \mathrm{a}$ pyrazosulfuron-ethyl.

$\square$; treated, $\square$; control 
kept in a greenhouse maintained at $20^{\circ} \mathrm{C}$ day/ $30^{\circ} \mathrm{C}$ night under non-leaching conditions. All experiments were replicated three times.

\section{Results and Discussion}

\section{The number and fresh weight of} tubers

In both the pre-and post-emergence treatments, pyrazosulfuron-ethyl decreased the total number and total fresh weight of tubers transplanted to a depth of $7.5 \mathrm{~cm}$ to ca. 60 $\%$. These inhibitory effects diminished significantly in tubers transplanted to a $15 \mathrm{~cm}$ depth; the total number of tubers increased as compared to control (Fig. 1). Thus, pyrazosulfuron-ethyl was found to strongly suppress the tuberization of Eleocharis kuroguwai emerging from shallower portions but not of those from deeper portions in soil.

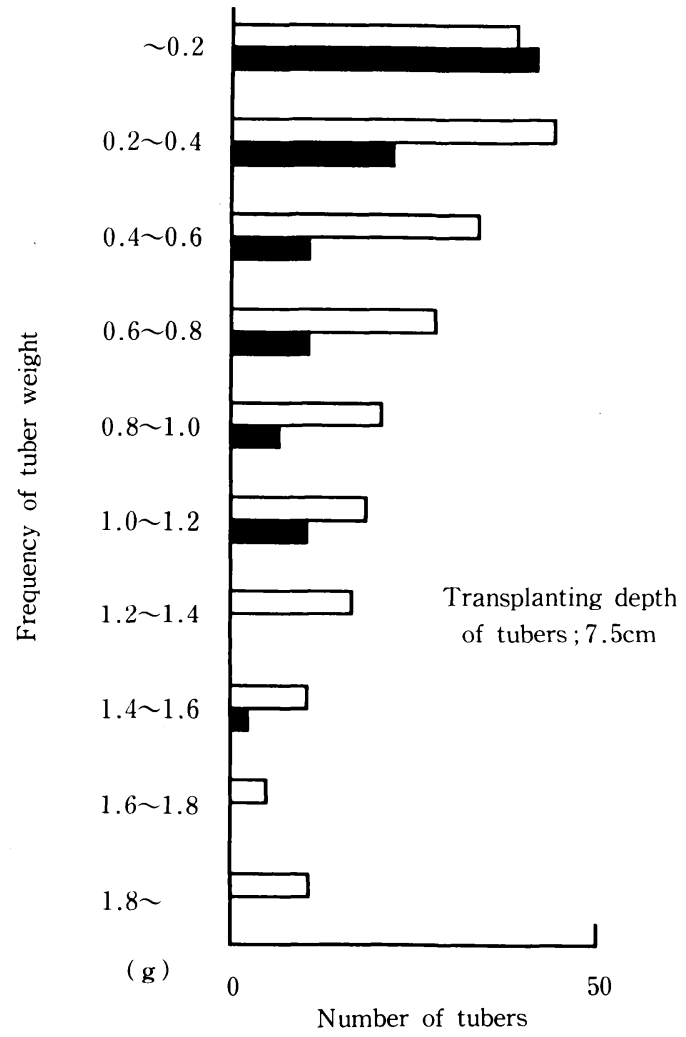

\section{Frequency distribution of tuber weight}

In the pre-emergence treatment, the number of tubers in all weight classes decreased remarkably at the tuber transplanting depth of $7.5 \mathrm{~cm}$. However, at the clear without repeating depth of $15 \mathrm{~cm}$, the number of smaller tubers in the three weight classes, $<0.2 \mathrm{~g}$, $0.2 \sim 0.4 \mathrm{~g}$ and $0.4 \sim 0.6 \mathrm{~g}$, increased notably as compared to control (Fig. 2). In the postemergence treatment, the number of tubers decreased except for that in the lightest weight class $(<0.2 \mathrm{~g})$ at the transplanting depth of $7.5 \mathrm{~cm}$ (Fig. 3). These results suggest that pyrazosulfuron-ethyl does not primarily inhibit the tuberization of Eleocharis kuroguwai but the enlargement of the tubers. Therefore, the herbicide treatment increased the number of smaller tubers as shown in

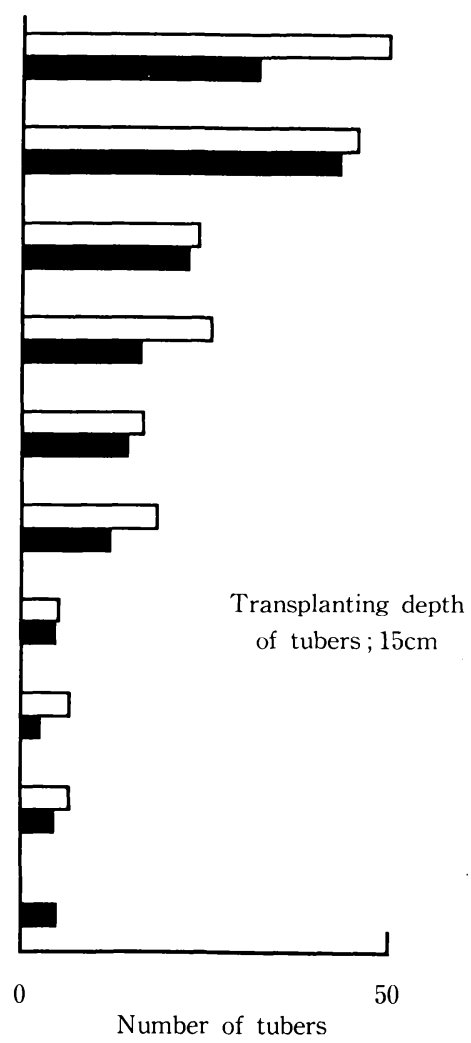

Fig. 3. Frequency distribution of tuber weight of Eleocharis kuroguwai after post-emergence treatment with $0.21 \mathrm{~g} / \mathrm{a}$ pyrazosulfuron-ethyl.

; treated, $\square$; control 

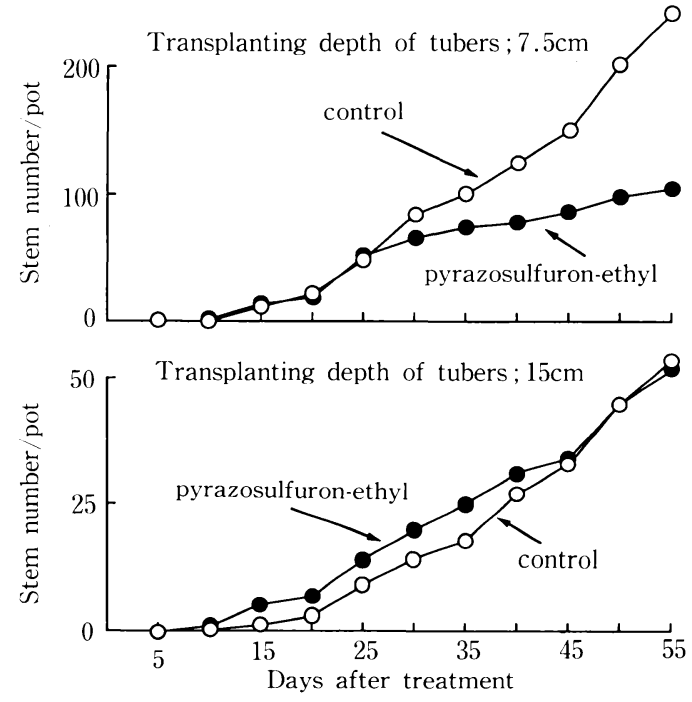

Fig. 4. Effect of pyrazosulfuron-ethyl $(0.21 \mathrm{~g} / \mathrm{a})$ on the emergence of Eleocharis kuroguwai by pre-emergence treatment.

Fig. 1. This tendency became clear when the mother tubers were in deeper portions of the soil.

\section{Stem number}

When the tubers were transplanted $7.5 \mathrm{~cm}$ deep in soil, the weed in both the treated and untreated plots emerged similarly until 25 days after treatment, while the emergence patterns thereafter were different; the stem number in the former was less than that in the latter and the difference between these plots became greater with time. At the tuber transplanting depth of $15 \mathrm{~cm}$, however, inhibition of the emergence was not observed (Fig. 4).

Consequently, pyrazosulfuron - ethyl was found to strongly suppress the tuber number, tuber weight and stem number of Eleocharis kuroguwai emerging from shallower areas of the soil, but the inhibition diminished when the weed emerged from deeper areas. When the tubers were transplanted $15 \mathrm{~cm}$ deep and the herbicide treatment was made at the emergence of the weed, the plumules would be exposed to the herbicide. It was therefore considered that the herbicide was little absorbed through the plumules, or that the major absorbing parts were lower portions of the weed, presumably the root differentiating parts. In addition, when the tuber transplanting depth was $15 \mathrm{~cm}$ and the herbicide was treated just after the transplanting, observed decrease in the inhibition may not have been due to the lack of residual activity of the herbicide; the weed needed ca. 18 days for emergence from the $15 \mathrm{~cm}$ depth as shown in Fig. 4, but the herbicide would persist in the soil for a longer period.

If the herbicide is mainly absorbed through the root differentiating parts of the weed, the chemical would not be active without a downward mobility to reach that part. Many factors may influence herbicidal activity, however, mobility in the soil and absorbent portions of the weed appear to be major factors affecting that against Eleocharis kuroguwai.

\section{References}

1) Kobayashi, H. and K. Ueki 1983. Phenotype variation and adaptation in Eleocharis kuroguwai Ohwi, a paddy perennial Cyperaceous weed. Weed Res. Japan 28, 179-186.

2) Kusanagi, T. 1984. Studies on the reproductive characteristics of perennial weeds in paddy fields and their control. Weed Res. Japan 29, 255-266 (in Japanese with English summary).

3) Itoh, K. and Y. Watanabe 1983. Effect of the variation in the water level on the growth and formation of propagules in four Alismataea paddy weeds. Weed Res. Japan 28, 187-193 (in Japanese with English summary).

4) Yamagishi, A. 1983. Cyperus serotinus Rottb., on its physiological and ecological characteristics and control measures. Weed Res. Japan 28, 243-259 (in Japanese with English summary).

5) Yamagishi, A. and Y. Takeichi 1978. Studies on the control of some perennial Weeds in paddy field. VIII. On the Physiological and ecological characteristics of Water chestnuts (Eleocharis kuroguwai). Bull. Chiba Agric. Exp. Stn., 19, 191-217 (in Japanese with English summary). 